\title{
AOR
}

Selected Papers of \#AolR2020:

The $21^{\text {st }}$ Annual Conference of the

Association of Internet Researchers

Virtual Event / 27-31 October 2020

\section{GLOBAL PERSPECTIVES OF WORK-RELATED IMPACTS TO DIGITAL WELL-BEING BY SOCIAL MEDIA PROFESSIONALS - A PILOT STUDY}

Karen Sutherland

University of the Sunshine Coast

\section{Introduction}

The pervasiveness of social media has resulted in the establishment of a new career sector to manage the digital marketing, communications, public relations and advertising activities for businesses, nonprofits and high-profile individuals (McCosker, 2017). Consequently, the lines between work and personal lives have blurred, when constant connection and working across time-zones can be job requirements for workers providing social media support. Studies investigating digital labour, boundary management and Post-Fordism have explored technology's impact on working conditions, but few have specifically examined the perspectives of social media professionals. This pilot study provides an insight into the perceptions of 15 social media professionals from six continents, to examine if current working conditions have impacted their health and well-being.

\section{Literature Review}

Defined as "...the ability to look after personal health, safety, relationships and work-life balance in digital settings," digital well-being has evolved as an area of interest in response to the increased adoption of smartphones and social media (Shah \& Knight, 2012, p.6). Digital well-being is an emerging area of examination in social media employment sectors. However, an extensive body of related research exists investigating digital labour and Post-Fordism resulting from technological evolution and its impacts to work-life balance, suggesting the lines between work and personal lives have not only blurred, they have dissolved (Ciolfi \& Lockley, 2018; Kneese, et al., 2014). Research exploring social media professionals has focused on specific countries and geographical regions (e.g. Australia and Europe). Results suggest social media workers experience intrusion into their personal lives, increased workload and a lack of organisational policies in place to protect their well-being (Bucher, Fieseler \& Suphan, Sutherland, K. (2020, October). Global Perspectives of Work-Related Impacts to Digital Well-Being by Social Media Professionals - A Pilot Study. Paper presented at AolR 2020: The 21 th Annual Conference of the Association of Internet Researchers. Virtual Event: AolR. Retrieved from http://spir.aoir.org. 
2013; McCosker, 2017; van Zoonen et al., 2017). The current pilot study differs from previous research because it provides an initial global snapshot exploring experiences of social media professionals from six continents and a deeper analysis into current impacts, risk mitigation strategies and perceived duty-of-care relating to social media responsibilities in the workplace using the following research questions:

RQ1: Do social media professionals perceive any requirements of their role have impacted their health and well-being?

RQ2: Do social media professionals believe the responsibility for work-related digital well-being should rest with the employee or the employer?

RQ3: What measures have been implemented by social media professionals and/or their employers to promote digital well-being in the workplace?

\section{Method}

Purposive sampling was used to source participants for this study. With approval from the author's home institution's Human Research Ethics Committee, Linkedln searches were used to identify professionals working in various social media roles from a range of countries. The aim was to source a sample that was balanced in gender and geographical spread. Requests to participate were sent via Linkedln's messaging function. Twenty requests were sent, five did not receive any response. Fifteen people responded expressing interest in participating.

The sample was comprised as follows:

Table 1. Sample Breakdown

\begin{tabular}{|l|l|l|}
\hline \multicolumn{1}{|c|}{ Country } & No. of Women & No. of Men \\
\hline Australia & 2 & \\
\hline Hong Kong & & 1 \\
\hline India & 2 & \\
\hline Mexico & 1 & \\
\hline South Africa & & 1 \\
\hline Sweden & 1 & \\
\hline United Kingdom & 1 & \\
\hline United States of America & 1 & 5 \\
\hline Total & & \\
\hline
\end{tabular}


Semi-structured interviews were used to gather data as they provide flexibility and facilitate detail-rich responses when the research is limited to specific topic areas (Weerakody, 2015). Furthermore, semi-structured interviews are more appropriate with a smaller sample as per this pilot study.

Interview responses were recorded in-person, via Zoom video conferencing or by email. The method was dependent on the participant's preference and availability due to the time difference across world regions. A Grounded Theory approach and inductive analysis were the most appropriate methods of data analysis in this study. Data was coded in three stages using NVivo: 1. Open Coding, 2. Axial Coding and 3. Selective Coding to identify patterns and relationships within interview responses.

\section{Preliminary Results}

\section{RQ1}

Common themes highlighted by participants included the inability to disconnect from work during their personal time, feelings of stress when managing live events/campaigns, including livestreaming, and being exposed to negative comments and messages when managing online communities.

\section{RQ2}

The majority of respondents perceived the responsibility for digital well-being to be equally shared between employer and employee. Two participants responded that the duty-of-care rests solely with the employer.

\section{RQ3}

Three participants identified measures implemented at their workplaces to promote digital well-being. Such measures included a weekly email tracking each employee's "online" time and processes to ensure that employees were not overloaded. One participant's workplace had a technology-free "pause area" where employees could go for a break.

Strategies implemented by participants to maintain their personal digital well-being included: spending time outside, taking regular breaks from the phone/computer, turning on the "Do Not Disturb" mode on their iPhone when sleeping.

\section{Discussion}

In line with previous research relating to digital labour, Post-Fordism and boundary management, preliminary results in this pilot study suggest that the majority of social media professionals experience stress, an inability to disconnect from technology and intrusion into their personal lives as a result of their occupation (Bucher, Fieseler \& Suphan, 2013; McCosker, 2017; van Zoonen et al., 2017; Ciolfi \& Lockley, 2018; Kneese, et al., 2014). While Post-Fordism discourse suggests technological advances have changed the nature of work and workplaces, this study proposes employers are yet to acknowledge such shifts reducing action to minimise impacts to promote digital well-being among employees. Employers may perceive their duty-of-care ends when 
social media professionals leave work for the day even though their responsibilities can follow them home. These findings suggest further research is required to provide greater insight into the blurring of work and personal lives from employer and employee perspectives for people working in social media-related fields.

\section{Conclusion}

This pilot study provided a glimpse into the global perspectives of work-related impacts to digital well-being by social media professionals. Results highlighted a disconnect between social media professionals and their workplaces, and the blurring of lines between work and personal lives. This research is the beginning of a more comprehensive study that will include a much larger global sample of social media professionals and employers, utilising research methods such as surveys, interviews and on-site observation within organisations.

\section{References}

Bucher, E., Fieseler, C., \& Suphan, A. (2013). The stress potential of social media in the workplace. Information, Communication \& Society, 16(10), 1639-1667.

Ciolfi, L., \& Lockley, E. (2018). From Work to Life and back again: Examining the digitally-mediated work/life practices of a group of knowledge workers. Computer Supported Cooperative Work (CSCW), 27(3-6), 803-839.

Kneese, T., Rosenblat, A., \& Boyd, D. (2014). Understanding fair labor practices in a networked age. Open society foundations' future of work commissioned research papers.

McCosker, A. (2017). Social media work: Reshaping organisational communications, extracting digital value. Media International Australia, 163(1), 122-136.

Roffarello, A. M., \& De Russis, L. (2019). The Race Towards Digital Wellbeing: Issues and Opportunities. In CHI (p. 386).

Shah, A. \& Knight, S. (2012). Digital Wellbeing Workshop. JISC, viewed 04.02.2020: https://aptconference.org.uk/index.php/apt/apt2019/paper/view/1382/568

van Zoonen, W., Verhoeven, J. W., \& Vliegenthart, R. (2017). Understanding the consequences of public social media use for work. European Management Journal, 35(5), 595-605.

Weerakkody, N. (2015). Research Methods for Media and Communication Second Edition. Oxford University Press: South Melbourne. 